\title{
Finding a path to growth as a leader: a medical learner perspective
}

\author{
David A Benrimoh, ${ }^{1}$ Jordan D Bohnen, ${ }^{2}$ Justin N Hall ${ }^{3}$
}

${ }^{1}$ Department of Psychiatry, McGill University, Montreal, Quebec, Canada ${ }^{2}$ Department of Surgery, Massachusetts General Hospital and Harvard Medical School, Boston, Massachusetts, USA ${ }^{3}$ Division of Emergency Medicine, University of Toronto, Toronto, Ontario, Canada

Correspondence to Dr David A Benrimoh, Department of Psychiatry,

McGill University Health Centre, Montreal, QC H3G 1A4, Canada; david.benrimoh@mail.mcgill.ca

Received 31 January 2018 Revised 20 March 2018 Accepted 17 April 2018 Published Online First 2 May 2018
Check for updates

To cite: Benrimoh DA, Bohnen JD, Hall JN. BMJ Leader 2018:2:56-58.

\section{ABSTRACT}

Physicians are often required to lead teams in clinical and non-clinical environments but may not receive formal training in advance of these opportunities. In this commentary, three medical learners discuss their views on leadership education in undergraduate and postgraduate medicine, arguing that leadership development should be more explicitly integrated into training programmes and that medical leaders need to be better recognised for their contributions to this field, much like expert clinicians, clinicianeducators and clinician-scientists are recognised for theirs. After reviewing the published literature in this domain, reflecting on their experiences engaging with medical leaders and attending a leadership education summit, the authors conclude that, as initial steps towards improving leadership training in medical education, faculties and programmes should commit to incorporating leadership training into their curricula, and strive to deliberately connect learners interested in leadership with practising clinician-leaders with an eye towards improving learners' leadership skills. These first steps could help to catalyse the necessary shift towards improved leadership education and better patient care.

\section{LEADERSHIP EDUCATION IN MEDICAL TRAINING}

Physicians often find themselves in situations where they can lead, but are they well prepared for this role based on their formal training? Medical learners often experience a disconnect between what is valued on applications to medical school, residency programmes and staff positions, and what is emphasised in medical training. This disconnect is evident in the case of leadership. Competency frameworks such as CanMEDS 2015, CanMEDS-FM and the ACGME Core Competencies ${ }^{1-3}$ endorse leadership skills as a core competency of physicians. Moreover, competitive medical schools and residency programmes seek candidates with demonstrated leadership experiences. It is therefore paradoxical that leadership education remains an under-emphasised component of medical school and residency curricula. While a primary objective of medical training is to produce expert clinicians to deliver high-quality care, committing to leadership skills development for learners has the potential to significantly improve healthcare quality more broadly. For example, enhancing leadership skills of developing clinicians is likely to improve clinician effectiveness by preparing practitioners for clinical teamwork and the numerous leadership and administrative roles that directly affect, and can dramatically improve, patient care. ${ }^{4}$ Fortunately, in recent years, there have been many calls to improve leadership training in medical education programmes, and some notable progress has been made at both the undergraduate and postgraduate levels. ${ }^{5-11}$

For example, some undergraduate medical programmes, such as the University of Toronto, offer a master's degree or certificate in leadership to a select group of interested students. ${ }^{5}$ To enhance leadership and advocacy training for all students, the University of Manitoba has incorporated a workshop that teaches medical students to write letters to their members of parliament about healthcare-related issues. ${ }^{5}$ Across Canada and the USA, medical students are supported by their faculties to attend 'lobby days', events where groups of medical students meet with local and national politicians to discuss issues such as universal drug coverage; many faculties also support programmes where students or physicians offer mentorship on the leader role. ${ }^{5}$ Blumenthal and colleagues ${ }^{8}$ describe implementing a pilot leadership curriculum for internal medicine residents consisting of case studies and discussions about leadership at the clinical level and note that participants found that the course provided content and skills training relevant to their daily roles. This course has become required for all internal medicine residents in the programme. Two systematic reviews published within the last 5 years identified nearly 70 different curricular efforts in leadership development, many of which target medical students and trainees. ${ }^{12} 13$ Still, much work remains to be done because many of these activities only provide leadership experience to those already interested in leadership, and where universal programmes exist, they often are not as rigorous as other aspects of medical training.

As learners we perceive that time spent on leadership training is still undervalued by faculty and training programmes. This has the effect of shaping a 'hidden curriculum, ${ }^{14}$ which teaches some learners to devalue this skillset as well.

\section{WHY DO PROGRAMMES UNDERVALUE LEADERSHIP SKILLS TRAINING?}

Below we discuss three potential explanations for why leadership skills development may be undervalued in medical education.

First, educators may not believe that leadership skills can or should be systematically taught; rather these skills should be gleaned through experience in the clinical setting, and with time and deliberate practice, one will become more proficient. This may be compounded by the belief that one becomes more comfortable wielding authority and more capable as a leader as a direct result of clinical experience and growing clinical competence. This 
is problematic, however, as previous research shows that leadership skills can be effectively taught to clinicians. ${ }^{73}$ Furthermore, repeated calls for improved leadership teaching demonstrate that the status quo is not effectively preparing medical learners for leadership roles. ${ }^{67}$

Second, medical educators may believe that their learners, having been accepted into competitive medical schools and/or residency programmes, are a population of learners who have already acquired leadership abilities or who do not need additional leadership training. Yet, leadership skills can be continuously improved through dedicated efforts, for example, through iterative cycles of experience, reflection and feedback. ${ }^{4}$ Additionally, the leadership challenges that clinicians face are often specific to the clinical setting in which they work. Healthcare is a complex, high-stake and often high-stress environment which is very different from the undergraduate extracurricular activities or the workplace experiences that serve as the most common sources of leadership experience for medical school applicants. Given these realities, it is imperative that leadership skills be developed in the healthcare setting to better ensure they can be deployed at the appropriate times to ensure high-quality care. To do so, leadership development efforts must also be structured intelligently and promoted by clinicians, medical educators and clinician-scientists. It is only when this training is valued by our supervisors that the hidden curriculum can change and that more learners will start to value, develop and demonstrate enhanced leadership skills. Learners who value leadership skills are also more likely to develop a commitment to lifelong learning about leadership and to critically reflect on their own leadership as they direct their own growth through deliberate practice.

Third, some may hold the belief that leadership training should be reserved for the subset of individuals with an expressed interest in becoming systems leaders, and therefore may not be relevant to all learners. However, as Dath and colleagues ${ }^{9}$ argue, leadership is an important part of the day-to-day work of all clinicians. While some schools have established leadership programmes, gaps in medical curricula that currently exist leave many graduates of medical training programmes unprepared for these 'small l' leadership roles. 'Small l' leadership refers to leadership at the level of a clinic or multidisciplinary team, as opposed to leadership at the systems level, and has as its goal the creation and maintenance of an effective care environment; all clinical personnel, from medical students to nurses to consultants, may need to act as small 'l' leaders at different times. ${ }^{15}$ Filling in these gaps could result in stronger leadership at every level of the healthcare system, from frontline providers and clinical teams to administrators, improving patient care and the efficiency with which services are delivered.

\section{ENGAGING WITH THE MEDICAL LEADERSHIP EDUCATION COMMUNITY}

We have highlighted some of the barriers that may prevent leadership development from being universally integrated into medical curricula. How can these concerns be addressed?

It is perhaps not surprising that one way to improve the delivery of leadership education and to provide more opportunities for medical learners to grow as leaders is through engaging in leadership itself. To demonstrate this, we reflect below on some of our own experiences engaging with the medical leadership community. Lessons learnt through these interactions offer hope that similar interactions could facilitate others' growth as leaders, and in doing so, catalyse a shift toward improved leadership education throughout the medical education system.
Exposure to different career paths in medicine begins on day 1 of training through the role models honoured by our faculties. Master-clinicians, clinician-scientists and increasingly clinician-educators are recognised for their contributions. With the exception of clinicians with formal leadership titles (eg, Chair, Chief and Programme Director), frontline healthcare leaders are less often singled out for their leadership contributions. As such, we are more familiar with the archetypes of clinician-expert, clinician-scientist and clinician-educator than clinician-leader.

In contrast, when we first attended the Toronto International Summit on Leadership Education for Physicians (TISLEP), we were exposed to a diverse community of clinician-leaders who were passionate about physician leadership. Many of these leaders were engaged in transformational change in the healthcare and medical education systems including leading the change to competency-based medical education and the reorganisation of healthcare services. Despite this, their work was often less well known to learners and colleagues outside the medical leadership community (though there are certainly examples of wellknown clinician-leaders). This led us to realise how undervalued clinician leadership is and how little we had been exposed to clinician-leader role models. By attending this conference, we had the opportunity to engage with thought leaders on the topic of medical leadership. It also provided us with a chance to learn and apply leadership skills through workshops and participation on organising committees. There, we engaged with learners from undergraduate and postgraduate medicine, staff physicians, policy-makers, other healthcare professionals, faculty from outside of healthcare and patients. Learner opinions were frequently sought after and valued. Through this experience, we networked with junior and senior clinicians who demonstrated their commitment and passion to improving leadership education by developing resident modules ${ }^{16}$ that could be used freely by medical educators and learners. The summit organisers and attendees valued leadership and leadership education, as well as our contributions and interest as learners. The summit also served as a gateway to other academic opportunities.

This experience highlighted for us the importance of experiential learning in leadership education. Leadership is a skill that must be taught and practised. ${ }^{5}$ In our case, the experience of working with senior colleagues who valued our contributions empowered us to pursue further leadership development opportunities. Attending TISLEP provided theoretical foundations to inform this development; actively engaging as conference organisers provided a forum to translate theory into action. Clinicians who actively engage in leadership at the experiential level, and who reflect on these experiences with an eye towards refining their skills, will be more likely to understand their leadership strengths and weaknesses as they take on additional leadership roles in the future.

\section{OVERCOMING BARRIERS TO LEARNER ENGAGEMENT}

The experience of attending and then helping organise TISLEP, combined with our previous and concurrent experiences engaging in leadership and advocacy locally, provincially and nationally with various student, resident and physician organisations, have motivated us to continue our efforts to improve medical leadership education. When learners are exposed to mentors who value leadership and who respect and engage the learner-and provide them with space to become leaders themselves-engagement in leadership training is likely to increase. This engagement is most likely to occur in an environment where there is a shared commitment to physician leadership 
and leadership education between faculty and learners. TISLEP provided this supportive environment. However, conferences are self-limited and not every trainee has the opportunity to attend. One mechanism we have found helpful is to connect with local clinician-leaders and to maintain and expand the international networks we established through TISLEP. This deliberate expansion fosters a strong sense of community and helps sustain momentum. However, it is often a time-consuming and challenging process when done alone. As such, while having more learners attend educational events focused on medical leadership will certainly have a positive impact (as it did in our case), it is unlikely to be a scalable solution-that is, we cannot rely on these types of conferences to, in isolation, train the next generation of medical leaders. Instead we encourage medical schools and postgraduate training programmes to help link students with clinician-leader mentors and to foster a culture within each programme that is conducive to the growth of learners interested in leadership skills development.

Several strategies to promote clinician-leadership are available. One is to publicly acknowledge and celebrate our physician leaders by raising their profile through awards or faculty communications. This recognition will help learners recognise that becoming a clinician-leader is a viable path for career development. Another is to create more faculty promotion and tenuretrack pathways to develop and promote physician leaders like their clinician-educator and clinician-scientist colleagues. This expertise will help faculties develop and implement new leadership curricula that will benefit all learners. This cultural shift will require leadership and a willingness of training programmes to actively address the hidden curriculum which has, in general, devalued leadership education. As a step towards programmes aimed at teaching leadership skills to all learners, wider implementation of dual-degree or elective certificate-granting programmes like the ones described above will help to deepen the skills of learners interested in leadership, potentially empowering them to contribute to the further development of leadership training opportunities. Another positive development would be wider programme support for elective or extracurricular leadership projects or training experiences, as these opportunities foster skills development, and working on projects of their own choosing should improve learners' engagement with leadership education. Ultimately, though, we believe that foundational leadership skills training should be incorporated into all residency programmes to provide healthcare trainees with the leadership skills and confidence needed to excel as leaders in today's healthcare system.

We also call on current physician leaders to reach out to students and residents. There are certainly medical learners who are seeking role models and who would be interested to engage with and learn from local leaders through leadership curricula and other hands-on experiences. This engagement would help interested learners sustain their efforts to work with programmes to improve leadership education. Finally, programmes and organisations must be willing to listen to and value these learner voices while working alongside learners to set the agenda for change.

Acknowledgements The authors would like to acknowledge the support and advice of Anne Matlow, MD, FRCPC, from the University of Toronto, and Ming-Ka Chan, MD, MHPE, FRCPC, from the University of Manitoba, whose valuable input helped refine and improve this work.

Contributors DAB produced the outline and conceptualised the review; submitted the study and is responsible for the overall content as the guarantor. All authors provided narrative comments about their experiences as developing medical leaders and collaborated on producing a common narrative thread; contributed to writing and editing of the manuscript.

Funding The authors have not declared a specific grant for this research from any funding agency in the public, commercial or not-for-profit sectors.

Competing interests None declared.

Patient consent Not required.

Provenance and peer review Not commissioned; externally peer reviewed.

(c) Article author(s) (or their employer(s) unless otherwise stated in the text of the article) 2018. All rights reserved. No commercial use is permitted unless otherwise expressly granted.

\section{REFERENCES}

1 Frank JR, Snell L, Sherbino J. CanMEDS 2015 physician competency framework. Ottawa, ON: The Royal College of Physicians and Surgeons of Canada, 2015.

2 Shaw E, Oandasan I, Fowler N. CanMEDS-FM 2017: a competency framework for family physicians across the continuum. Ottawa, ON: The College of Family Physicians of Canada, 2017

3 ACGME. Common Program Requirements. 2017 http://www.acgme.org/Portals/0/ PFAssets/ProgramRequirements/CPRs_2017-07-01.pdf (accessed 27 Jan 2018).

4 Blumenthal DM, Bernard K, Bohnen J, et al. Addressing the leadership gap in medicine: residents' need for systematic leadership development training. Acad Med 2012;87:513-22

5 Benrimoh D, Warsi N, Hodgson E, et al. An Advocacy and Leadership Curriculum to Train Socially Responsible Medical Learners. MedEdPublish 2016;5.

6 Maddalena V. Leadership training for undergraduate medical students. Leadersh Health Serv 2016;29:348-51.

7 Jardine $D$, Correa R, Schultz $\mathrm{H}$, et al. The need for a leadership curriculum for residents. J Grad Med Educ 2015;7:307-9.

8 Blumenthal DM, Bernard K, Fraser TN, et al. Implementing a pilot leadership course for internal medicine residents: design considerations, participant impressions, and lessons learned. BMC Med Educ 2014;14:257(1-11).

9 Dath D, Chan MK, CanMEDS AC. 2015 from manager to leader. Ottawa, ON: The Royal College of Physicians and Surgeons of Canada, 2015.

10 Matlow A, Chan MK, Bohnen JD, et al. Collaborating internationally on physician leadership education: first steps. Leadersh Health Serv 2016;29:220-30.

11 Chan MK, de Camps Meschino D, Dath D, et al. Collaborating internationally on physician leadership development: why now? Leadersh Health Serv 2016;29:231-9.

12 Webb AM, Tsipis NE, McClellan TR, et al. A first step toward understanding best practices in leadership training in undergraduate medical education: a systematic review. Acad Med 2014;89:1563-70.

13 Frich JC, Brewster AL, Cherlin EJ, et al. Leadership development programs for physicians: a systematic review. J Gen Intern Med 2015;30:656-74.

14 Hafferty FW, Franks R. The hidden curriculum, ethics teaching, and the structure of medical education. Acad Med 1994;69:861-71.

15 Bohmer R. Leadership with a small "I". BMJ 2010;340:c483.

16 Sanokondu. 2016. (Retrieved 11 Mar 2018). https://sites.google.com/site/sanokondu/ 